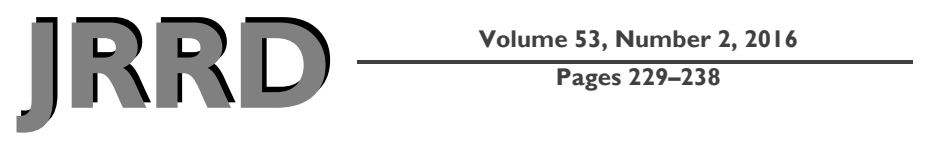

\title{
Gait kinematics and kinetics are affected more by peripheral arterial disease than by age
}

\author{
Sara A. Myers, PhD; ${ }^{1}$ Bryon C. Applequist, MS; ${ }^{1}$ Jessie M. Huisinga, PhD; $^{2}$ Iraklis I. Pipinos, MD; ${ }^{3}$ Jason $^{\mathrm{M}}$. \\ Johanning, MD $^{3 *}$ \\ ${ }^{1}$ Biomechanics Research Building, University of Nebraska Omaha, Omaha, NE; ${ }^{2}$ Physical Therapy and Rehabilitation \\ Sciences, University of Kansas Medical Center, Kansas City, KS; ${ }^{3}$ Department of Surgery, University of Nebraska \\ Medical Center, Omaha, NE; and Department of Surgery and Research Service, Department of Veterans Affairs \\ Nebraska-Western Iowa Health Care System, Omaha, NE
}

\begin{abstract}
Peripheral arterial disease (PAD) produces abnormal gait and disproportionately affects older individuals. The current study investigated PAD gait biomechanics in younger $(<65 \mathrm{yr})$ and older $(>/=65 \mathrm{yr})$ subjects. The study included 61 patients with PAD (31 younger, age: $57.4+/-5.3 \mathrm{yr}$, and 30 older, age: $71.9+/-5.2 \mathrm{yr}$ ) and 52 nondisabled age-matched control subjects. Patients with PAD were tested during pain-free walking and compared with control subjects. Joint kinematics and kinetics (torques) were compared using a 2 x 2 analysis of variance (groups: patients with PAD vs control subjects, age: younger vs older). Patients with PAD had significantly increased ankle and decreased hip range of motion during the stance phase as well as decreased ankle dorsiflexor torque compared with control subjects. Gait changes in older individuals are largely constrained to time-distance parameters. Joint kinematics and kinetics are significantly altered in patients with PAD during pain-free walking. Symptomatic PAD produces a consistent ambulatory deficit across ages definable by advanced biomechanical analysis. The most important finding of the current study is that gait, in the absence of PAD and other ambulatory comorbidities, does not decline significantly with age based on advanced biomechanical analysis. Therefore, previous studies must be examined in the context of patients with potential PAD being present in the population, and future ambulatory studies must include PAD as a confounding factor when assessing the gait function of elderly individuals.
\end{abstract}

Key words: aging, biomechanics, gait, gait decline, joint angles, joint torques, older adults, peripheral arterial disease, peripheral vascular disease, walking.

\section{INTRODUCTION}

Peripheral arterial disease (PAD) results in a significant decrease in blood flow to the lower limbs secondary to atherosclerosis within the pelvic and leg arteries. The most common symptom is intermittent claudication, a cramping pain occurring in the calves, thighs, and/or buttocks brought on by physical activity and relieved with rest. The end result of PAD is reduced mobility, reduced physical functioning, and poor health outcomes [1-4]. The prevalence of PAD increases as individuals age, with 4.3 percent of all Americans $>40$ yr old having PAD and 20 percent of Americans $>75$ yr old having PAD according to Hirsch et al. [5]. Based on this disproportionate occurrence of PAD in older adult populations, the total

Abbreviations: ANOVA $=$ analysis of variance, $\mathrm{NIH}=$ National Institutes of Health, O-CON = older control subjects, $\mathrm{O}-\mathrm{PAD}=$ older patients with PAD, PAD = peripheral arterial disease, $\mathrm{ROM}=$ range of motion, VA = Department of Veterans Affairs, Y-CON = younger control subjects, Y-PAD = younger patients with PAD.

*Address all correspondence to Jason M. Johanning, MD; Department of Surgery, VA Nebraska-Western Iowa Health Care System, 4104 Woolworth Ave (112), Omaha, NE 68105; 402-995-3608; fax: 402-559-8985.

Email: jason.johanning@va.gov

http://dx.doi.org/10.1682/JRRD.2015.02.0027 
number of patients affected by PAD is expected to increase according to current demographic predictions [6]. PAD will therefore significantly affect our older adult population by causing increased pain, discomfort, and fatigue. In addition, persons with PAD experience significant gait deficits, which result in reduced daily activity and loss of independence.

Gait changes in older adult individuals have been well-documented using biomechanical measures [7-11]. Older adults tend to walk slower and have shorter strides than young adults [7]. Older adults use their hip extensors more and their ankle plantar flexors and knee extensors less than younger nondisabled individuals, showing an overall reorganization of joint torques [12]. In addition, older adults tend to have a decreased range of motion (ROM) at the hip, knee, and ankle joints and spend more time in double support, which also increases overall stance time [10]. Despite a known high prevalence of PAD in the older adult population [13], no previous study in older individuals has taken into account that these measured changes in older adults may be due to the effect of PAD within the tested population. Our groups' work on PAD and aging $[7,11,14-17]$ led us to a recognition that the gait of older adult patients is very similar to the gait changes described for patients with PAD [14-15]. It is our concern, therefore, that elderly patients with unrecognized PAD have likely "contaminated" previous studies of older adult gait $[8,18]$.

Our research group has noted that many gait alterations previously identified in patients with PAD are similar to the gait changes documented in older adult subjects. Specifically, slower walking speeds, shorter strides [7,14-16], increased stance time [10-11,16-17], decreased ROM at the hip and knee during the stance phase, increased ankle ROM during the stance phase $[10,19-20]$, and reduced propulsion forces and push-off power $[11,15,17,21]$ have been noted in both populations. Our group has also reported kinetic changes in PAD gait. Specifically, patients with PAD have decreased joint torques [15,22-23] and powers [24] at the ankle and hip and exhibit reduced external work [25] compared with nondisabled age-matched control subjects. However, because many patients with PAD are also older adults, the independent effects of age and the disease are unknown. It is also unknown whether the effects of PAD and aging are additive. If gait truly worsens as patients age, then intervention in patients with PAD becomes even more important to preserve physical function and overall quality of life. This creates a need to examine the effects of age on gait parameters in patients with PAD.

The current study investigated the effect of age and PAD on gait mechanics using kinematics and kinetics in younger $(<65 \mathrm{yr})$ and older $(\geq 65 \mathrm{yr})$ patients with PAD and nondisabled age-matched control subjects. We hypothesized that patients with PAD would exhibit altered gait characteristics compared with nondisabled control subjects. We also hypothesized that gait characteristics would be different between younger and older groups. Finally, we hypothesized that if age affects gait parameters, then age and PAD would act synergistically, with the most significant gait alterations found in older adult patients with PAD.

\section{METHODS}

\section{Subject Inclusion and Exclusion Criteria}

The study consisted of 61 patients with PAD diagnosed with Rutherford class 2/Fontaine class 2 arterial occlusive disease with classic Rose intermittent claudication (Table 1). Subjects were arbitrarily considered younger ( $n=31)$ if $<65$ yr of age and older $(n=30)$ if $\geq 65$ yr of age based on the definition of the older adult population by the Centers for Disease Control and Prevention and the National Center for Health Statistics [26]. Patients with PAD were recruited from the vascular surgery clinics of the Department of Veterans Affairs (VA) Nebraska-Western Iowa Health Care System and the University of Nebraska Medical Center. In addition, 52 sex-, age-, height-, and body mass-matched nondisabled control subjects were recruited from the community (Table $\mathbf{1}$ ).

Patients with PAD and control subjects were screened and evaluated by one of two board-certified vascular surgeons (J.J. and I.P.). Patient evaluation included resting ankle-brachial index (a resting measurement $<0.90$ was present in all subjects with claudication), detailed history, and physical examination. Standard ankle-brachial index measurement was performed and consisted of blood pressure measurement at the brachial artery in the arm and the posterior tibial and dorsalis pedis arteries at the ankle. Control subjects had an ankle-brachial index $\geq 0.90$ and absence of subjective or objective ambulatory dysfunction. Control subjects were screened in a similar fashion as patients with PAD and were excluded for the same ambulation-limiting problems or if pain was experienced during walking. All subjects were screened to exclude any underlying cardiac, 
Table 1.

Subject demographics and clinical characteristics for younger ( $<65 \mathrm{yr}$ ) and older ( $\geq 65 \mathrm{yr})$ patients with peripheral arterial disease (PAD) and control subjects.

\begin{tabular}{lcccc}
\hline \multicolumn{1}{c}{ Characteristic } & $\begin{array}{c}\text { Y-PAD } \\
(\boldsymbol{n}=\mathbf{3 1})\end{array}$ & $\begin{array}{c}\text { O-PAD } \\
(\boldsymbol{n}=\mathbf{3 0})\end{array}$ & $\begin{array}{c}\text { Y-CON } \\
(\boldsymbol{n}=\mathbf{2 7})\end{array}$ & $\begin{array}{c}\text { O-CON } \\
(\boldsymbol{n}=\mathbf{2 5})\end{array}$ \\
\hline Sex $(n)$ & & & & 21 \\
$\quad$ Male & 26 & 30 & 20 & 4 \\
Female & 5 & 0 & 7 & $70.3 \pm 3.2$ \\
Age, yr (mean \pm SD) & $57.4 \pm 5.3$ & $71.9 \pm 5.2$ & $55.4 \pm 6.3$ & $82.3 \pm 13.2$ \\
Body Mass, kg (mean \pm SD) & $84.2 \pm 15.8$ & $83.9 \pm 17.4$ & $85.0 \pm 18.3$ & $170.9 \pm 8.6$ \\
Body Height, cm (mean \pm SD) & $172.8 \pm 6.7$ & $173.3 \pm 5.5$ & $173.6 \pm 8.5$ & $1.10 \pm 0.10$ \\
Ankle-Brachial Index (mean \pm SD) & $0.56 \pm 0.47$ & $0.53 \pm 0.67$ & $1.10 \pm 0.11$ & 12.0 \\
Smoker (\%) & 83.9 & 33.3 & 7.4 & 12.0 \\
Hypertension (\%) & 74.2 & 76.7 & 18.5 & 20.0 \\
Diabetes Mellitus (\%) & 9.7 & 36.7 & 0 & $28.14 \pm 3.75$ \\
Hyperlipidemia (\%) & 64.5 & 86.7 & 14.8 \\
Body Mass Index (mean \pm SD) & $28.08 \pm 4.37$ & $27.84 \pm 5.20$ & $28.08 \pm 4.63$ & 2.0 \\
\hline O-CON = older control subjects, O-PAD = older patients with PAD, SD = standard deviation, Y-CON = younger control subjects, Y-PAD = younger patients with \\
PAD.
\end{tabular}

pulmonary, neuromuscular, or musculoskeletal disease that would affect gait or make data collection unsafe. Therefore, both the patients with PAD and the nondisabled control subjects recruited for this study were somewhat unique in that they were excluded if they experienced pain or discomfort during walking for the following conditions: arthritis, low back pain, musculoskeletal problems, and neuropathy.

\section{Experimental Procedure and Data Collection}

Prior to data collection, reflective markers were placed at specific anatomical locations of each subject's lower limbs based on the marker systems of Nigg et al. and Vaughan et al. [27-28]. Each subject was directed to walk using their self-selected pace over a 10 m pathway while three-dimensional marker trajectories and ground reaction force data were simultaneously collected. The marker trajectories were captured with a 12-camera motion capture system (Motion Analysis Corporation; Santa Rosa, California) sampling at $60 \mathrm{~Hz}$. The ground reaction force data were acquired with a Kistler force platform (Kistler Instrument Corporation; Amhurst, New York) sampling at $600 \mathrm{~Hz}$. To assess baseline ambulatory functions, patients with PAD were tested in a pain-free condition. To ensure that patients did not experience pain during walking, a minimum of 1 min rest was required between each walking trial. Subjects completed five successful walking trials on each leg, with a successful trial being defined as the subject's foot being completely on the force platform. Subjects were positioned on the path- way so that they would step on the force platform while walking naturally.

\section{Data Analysis}

Time-distance gait variables were calculated using custom software in MATLAB (The MathWorks Inc; Natick, Massachusetts). Total ROM of the joint kinematics and peak values of the joint kinetics in the sagittal plane during the stance phase were analyzed (Figures 1-2). All marker trajectories were smoothed using a low-pass, fourth-order Butterworth filter (7 Hz cutoff) during postdata processing. Joint kinetics and kinematics were calculated for the stance phase from exported raw forces and marker trajectories using Visual3D software (C-Motion Inc; Germantown, Maryland). The joint torque values were scaled to body mass [11].

\section{Statistical Analysis}

Group means of the joint kinetics and kinematics were calculated by using the affected leg of unilateral patients and the side with the lowest respective anklebrachial index for bilateral patients in the PAD group, as well as the dominant legs of nondisabled control subjects (younger patients with PAD [Y-PAD], $n=31$; older patients with PAD [O-PAD], $n=30$; younger control subjects [Y-CON], $n=27$; and older control subjects [OCON], $n=25$ ). For each dependent variable, a $2 \times 2$ analysis of variance (ANOVA) was used with the factors being group (patients with PAD vs control subjects) and 

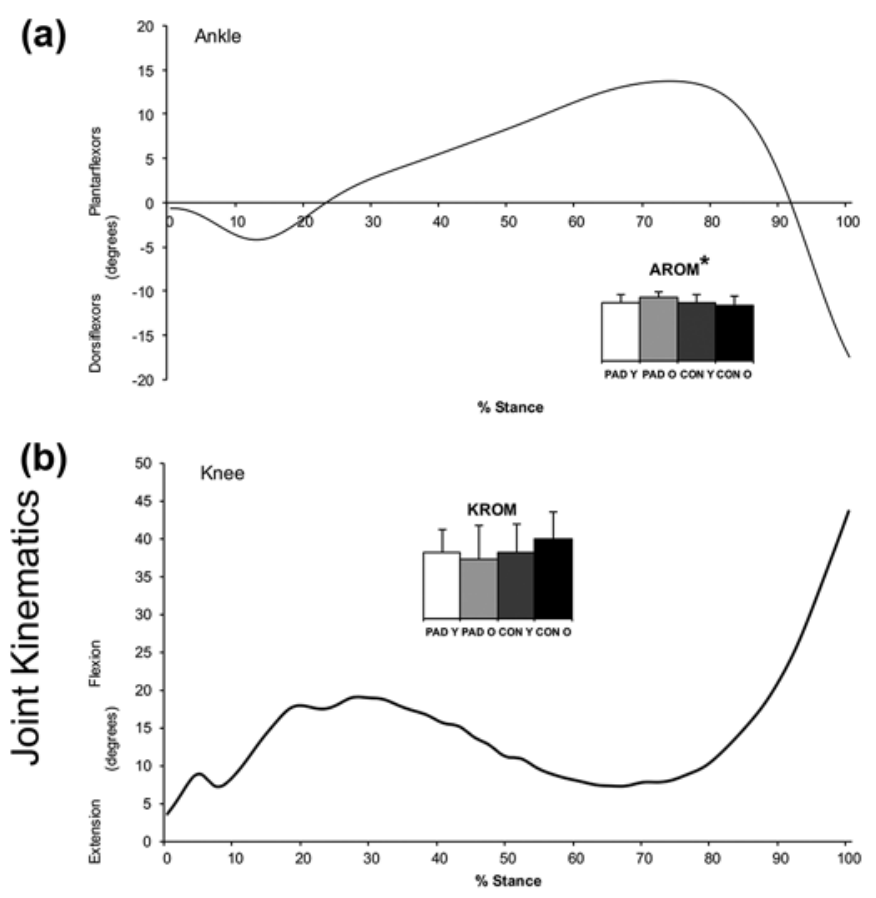

(c)

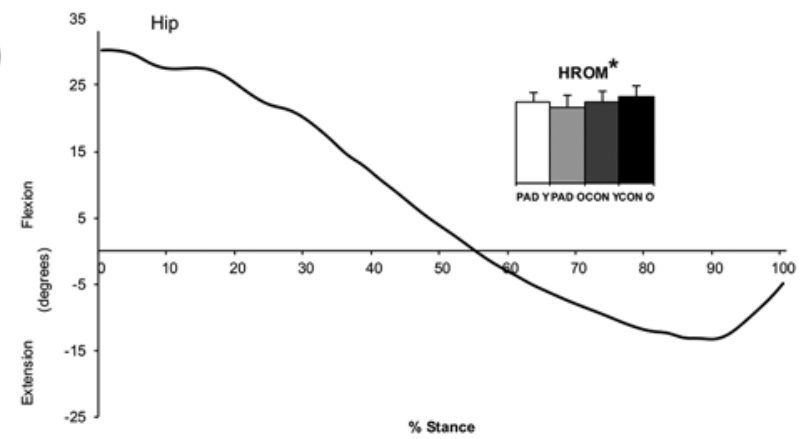

Figure 1.

Representative joint angle curves from younger $(<65 \mathrm{yr}$ ) nondisabled control subjects for (a) ankle, (b) knee, and (c) hip during stance phase. Bar graphs represent total flexion-extension range of motion (ROM) of corresponding curve. Patients with peripheral arterial disease (PAD) have more ankle ROM while also exhibiting less knee and hip ROM than control subjects. ${ }^{*} p<0.5$, significant main effect for group (patients with PAD vs control subjects). AROM = maximum ankle ROM during stance phase, $\mathrm{HROM}=$ maximum hip ROM during stance phase, $\mathrm{KROM}=$ maximum knee ROM during stance phase, $\mathrm{CON}-\mathrm{O}=$ older control subjects, $\mathrm{PAD}-\mathrm{O}=$ older patients with $\mathrm{PAD}, \mathrm{CON}-\mathrm{Y}=$ younger control subjects, PAD-Y = younger patients with PAD.

age (younger vs older). Group means for age, height, body mass, body mass index, and time-distance gait parameters were also compared using a $2 \times 2$ ANOVA.
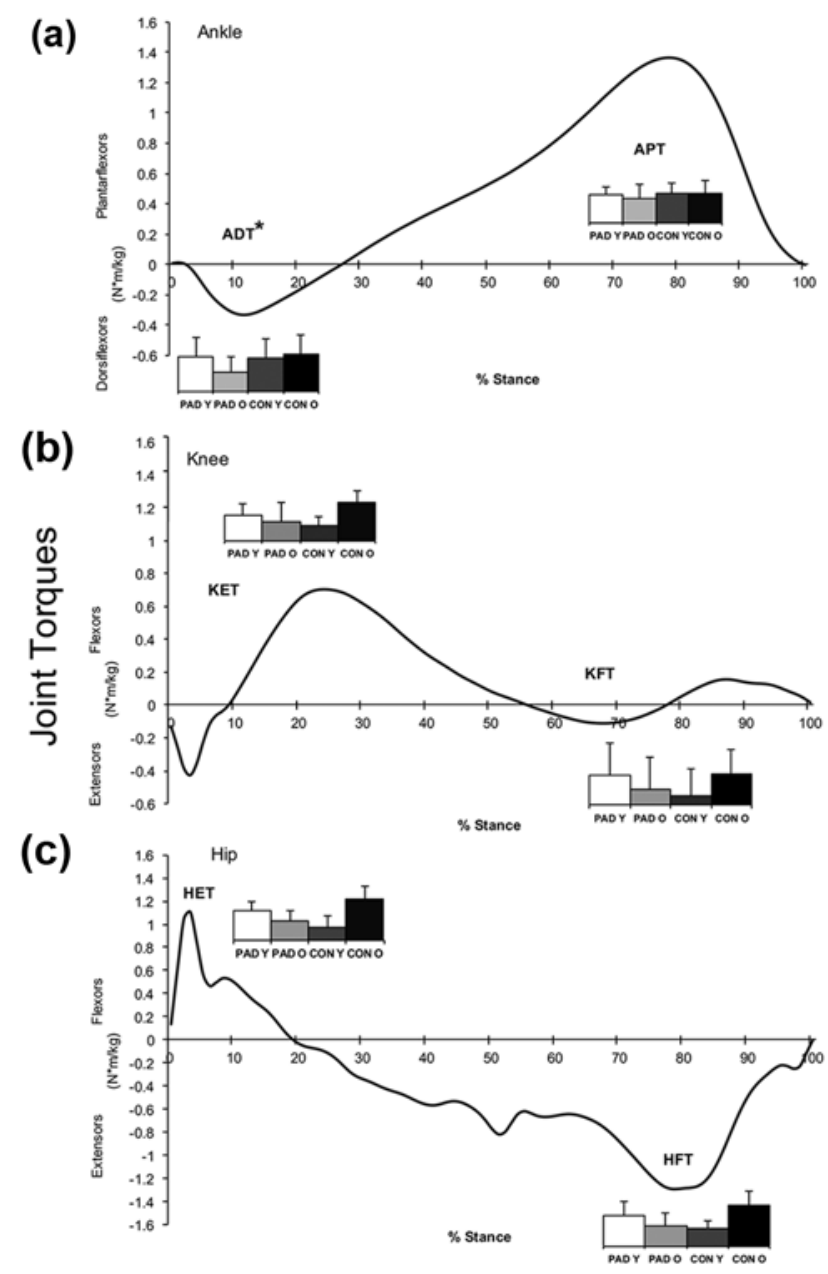

Figure 2.

Representative joint torque curves from younger ( $<65 \mathrm{yr}$ ) nondisabled control subjects for (a) ankle, (b) knee, and (c) hip during stance phase. Positive value indicates net internal extensor or plantar flexor torque; negative value indicates net internal flexor or dorsiflexor torque. Torques are normalized to body mass. Bar graph values represent peak torque of corresponding curves (units $=$ percent body weight $\times$ body height). Patients with peripheral arterial disease (PAD) have lower response of hip extensors during early stance, suggesting weakness of hip extensor muscles. Patients with PAD also have reduced ankle dorsiflexor and knee extensor torque during early stance and decreased hip flexor torque during late stance. ${ }^{*} p<0.5$, significant main effect for group (patients with PAD vs control subjects). $A D T=$ maximum ankle dorsiflexor torque, $\mathrm{APT}=$ maximum ankle plantar flexor torque, $\mathrm{HET}=$ maximum hip extensor torque, $\mathrm{HFT}=$ maximum hip flexor torque. KET = maximum knee extensor torque, $\mathrm{KFT}=$ maximum knee flexor torque, $\mathrm{CON}-\mathrm{O}=$ older control subjects, $\mathrm{PAD}-\mathrm{O}=$ older patients with $\mathrm{PAD}, \mathrm{CON}-\mathrm{Y}=$ younger control subjects, $P A D-Y=$ younger patients with $P A D$. 
When a significant interaction was identified, Tukey tests were used for post hoc analysis to identify significant differences between the group and/or age combinations. Statistical comparisons were performed using SPSS 22.0 (IBM Corporation; Armonk, New York). The level of significance was set at 0.05 .

\section{RESULTS}

\section{Demographics}

Table 1 presents the baseline clinical characteristics of the Y-PAD, O-PAD, Y-CON, and O-CON groups. Group means for age ( $p=0.31)$, height $(p=0.26)$, body mass $(p=0.27)$, and body mass index $(p=0.62)$ did not differ between patients with PAD and control subjects. Thus, patients with PAD and control subjects were wellmatched for anthropometric data, whereas clinical characteristics of the patients with PAD versus control subjects were significantly different, as was expected.

\section{Time-Distance Gait Parameters}

Significant main effect of group (patients with PAD vs control subjects) was found for cadence ( $F=5.39, p=$ 0.02) (Table 2). When compared with control subjects, patients with PAD had significantly decreased walking velocity ( $p<0.001)$, cadence $(p<0.001)$, stride length $(p<0.001)$, and stance phase percent of the total gait cycle $(p=0.02)$. Significant differences for age (younger vs older) also exist. Older subjects had decreased walking velocity ( $p=0.01)$, decreased step width $(p=0.05)$, and decreased stride length $(p=0.002)$. There were significant interactions between group and age. Specifically, Y-PAD subjects had decreased stride length $(p=0.003)$ compared with Y-CON subjects as well as increased step width ( $p=$ 0.03 ) and decreased cadence ( $p=0.009)$ compared with O-CON subjects. O-PAD subjects also had decreased stride length $(p=0.002)$, cadence $(p<0.001)$, and stance phase percent of the total gait cycle $(p=0.03)$ compared with O-CON subjects. Y-PAD subjects exhibited increased walking velocity $(p=0.001)$, stride length $(p=0.005)$, step length $(p=0.002)$, and stance phase percent of the total gait cycle $(p=0.03)$ compared with O-PAD subjects.

\section{Joint Angles}

Significant main effect of groups (patients with PAD vs control subjects) were detected for ankle ROM ( $F=$ 8.82, $p=0.004)$. Compared with control subjects, patients with PAD had increased ankle $(p=0.04)$ and decreased hip ( $p=0.005)$ ROM during stance (Table 3, Figure 1). No significant main effects for joint angles were observed for comparing Y-CON versus O-CON subjects. Additionally, there were significant interactions between group and age for joint angles. Specifically, Y-PAD subjects had decreased hip ROM ( $p=0.03$ ) compared with O-CON subjects and decreased knee ROM $(p=0.01)$ compared with O-PAD subjects. O-PAD subjects had increased ankle ROM compared with O-CON subjects $(p=0.004)$ and decreased knee $(p=0.02)$ and hip $(p=0.001)$ ROM compared with O-CON subjects (Table 3).

Table 2.

Group mean \pm standard deviation for selected time-distance gait parameters for younger ( $<65$ yr) and older ( $\geq 65$ yr) patients with peripheral arterial disease (PAD) and control subjects.

\begin{tabular}{|c|c|c|c|c|c|}
\hline Gait Parameter & $\begin{array}{c}\text { Y-PAD } \\
(n=31)\end{array}$ & $\begin{array}{l}\text { O-PAD } \\
(n=30)\end{array}$ & $\begin{array}{l}\text { Y-CON } \\
(n=27)\end{array}$ & $\begin{array}{l}\text { O-CON } \\
(n=25)\end{array}$ & Significance \\
\hline Gait Velocity (m/s) & $1.11 \pm 0.18$ & $0.98 \pm 0.22$ & $1.25 \pm 1.74$ & $1.19 \pm 0.22$ & $\mathrm{a}, \mathrm{b}, \mathrm{c}, \mathrm{d}$ \\
\hline Stride Length (m) & $1.33 \pm 0.13$ & $1.21 \pm 0.17$ & $1.43 \pm 0.13$ & $1.36 \pm 0.17$ & $a, b, c, d, e, f$ \\
\hline Cadence (steps/min) & $102.10 \pm 8.46$ & $100.20 \pm 6.15$ & $105.99 \pm 8.61$ & $108.63 \pm 9.66$ & a, c, f, g \\
\hline Step Length (m) & $0.64 \pm 0.11$ & $0.53 \pm 0.15$ & $0.67 \pm 0.13$ & $0.58 \pm 0.17$ & b, c, d \\
\hline Step Width (m) & $0.13 \pm 0.04$ & $0.11 \pm 0.04$ & $0.12 \pm 0.03$ & $0.10 \pm 0.05$ & $\mathrm{~b}, \mathrm{~g}$ \\
\hline Stance Phase (\% of gait cycle) & $66.27 \pm 2.12$ & $62.70 \pm 8.84$ & $66.30 \pm 1.53$ & $66.85 \pm 1.53$ & $\mathrm{a}, \mathrm{c}, \mathrm{d}, \mathrm{f}$ \\
\hline Swing Phase (\% of gait cycle) & $33.66 \pm 1.36$ & $33.56 \pm 1.69$ & $33.70 \pm 1.53$ & $33.15 \pm 1.91$ & - \\
\hline Double Support (\% of gait cycle) & $16.46 \pm 1.44$ & $17.02 \pm 1.15$ & $16.46 \pm 1.33$ & $16.70 \pm 1.69$ & - \\
\hline $\begin{array}{l}{ }^{\mathrm{a}} p<0.05 \text {, significant difference betw } \\
{ }^{\mathrm{b}} p<0.05 \text {, significant difference betv } \\
{ }^{\mathrm{c}} p<0.05 \text {, significant interaction bet } \\
\mathrm{d}_{p}>0.05 \text {, significant interaction bet } \\
{ }^{\mathrm{e}} p<0.05 \text {, significant interaction bet } \\
{ }_{\mathrm{f}}{ }_{p}<0.05 \text {, significant interaction betv } \\
{ }_{\mathrm{g}} p<0.05 \text {, significant interaction bet } \\
\text { O-CON = older control subjects, O-F }\end{array}$ & $\begin{array}{l}\text { (control subjects } \\
\text { (younger vs olde } \\
\text { and Y-CON. } \\
\text { and O-PAD. } \\
\text { and Y-CON. } \\
\text { and O-CON. } \\
\text { and O-CON. } \\
\text { patients with PA }\end{array}$ & ients with PAD). & bjects, Y-PAD & er patients wit & \\
\hline
\end{tabular}


JRRD, Volume 53, Number 2, 2016

Table 3.

Group mean \pm standard deviation for selected kinematic and kinetic parameters for younger ( $<65$ yr) and older $(\geq 65$ yr) patients with peripheral arterial disease (PAD) and control subjects.

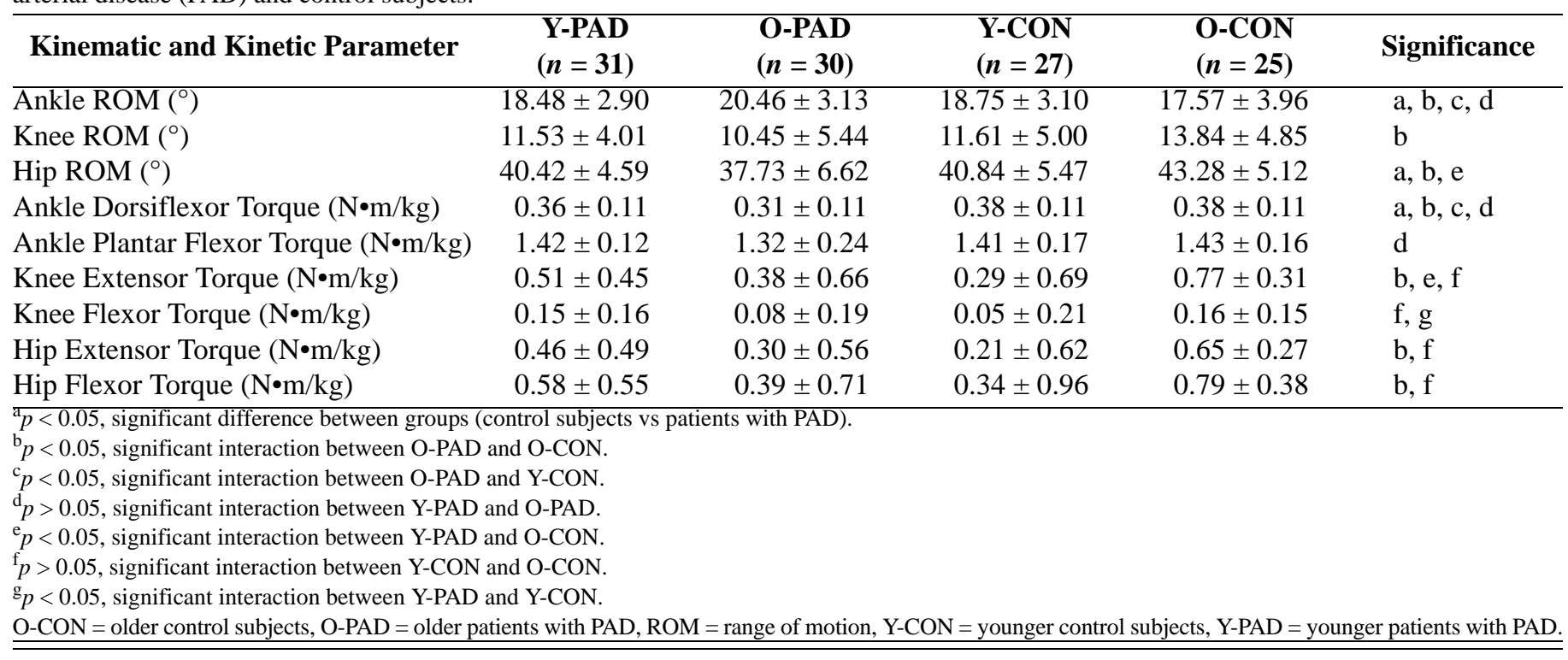

\section{Joint Torques}

A significant main effect for groups (patients with PAD vs control subjects) was detected for hip flexor torque $(F=6.31, p<0.01)$. Patients with PAD had significantly decreased ankle dorsiflexor torque in late stance compared with control subjects $(p=0.04$, Table 3, Figure 2). No differences were observed for age (younger vs older). There were significant interactions between group and age for joint torques. Specifically, YPAD subjects had greater knee flexor torque $(p=0.04)$ during stance compared with Y-CON subjects and decreased knee extensor torque $(p=0.02)$ during stance compared with O-CON subjects. Y-PAD subjects also had increased ankle plantar flexor torque $(p=0.04)$ compared with O-PAD subjects. O-PAD subjects had decreased ankle dorsiflexor torque $(p=0.02)$ during stance compared with Y-CON subjects. O-PAD subjects also had decreased ankle dorsiflexor torque $(p=0.03)$, knee extensor torque $(p=0.009)$, hip extensor torque $(p=$ $0.006)$, and hip flexor torque $(p=0.01)$ during stance compared with O-CON subjects.

\section{DISCUSSION}

The purpose of our study was to investigate the effect of age and PAD independently on gait mechanics using kinematics and kinetics in younger and older patients.
Because PAD occurs primarily in older individuals, it is imperative to determine the effect of aging and PAD on gait independently. Our hypothesis that gait characteristics would differ between patients with PAD and control subjects was supported by both the current study and our previous studies where time-distance parameters and joint kinematic and kinetic variables were different between patients with PAD versus control subjects. Interestingly, gait biomechanics did not decline significantly with age but only declined for time-distance variables, suggesting the effect of aging is not nearly as significant as the changes seen due to PAD. This suggests that the previous literature examining the gait of older patients failed to take into account the presence of PAD in the subjects and likely contaminated previous studies overemphasizing the effect of natural aging on gait function.

Previous studies have used joint kinematics [14,19], ground reaction forces [17], joint torques [15,23], and joint powers $[22,24]$ to study gait disability in patients with PAD. The present study is unique, being the first to use advanced biomechanical measures to examine the independent effect of aging and PAD on gait parameters. In our study, time-distance parameters, joint kinematics, and joint kinetics were evaluated while younger and older patients with PAD walked without claudication pain and were compared with younger and older nondisabled control subjects who were representative in sex, height, and body mass characteristics. Our results demonstrate 
that gait in patients with PAD is significantly affected prior to the onset of claudication pain. The time-distance parameters demonstrate a lethargic gait in patients with PAD, with reduced gait velocity, stride length, step length, and cadence and increased step width. These findings, like those in previous PAD studies, show altered timedistance parameters for patients with PAD [29]. The joint angle and joint torque data combined suggest that muscular weakness is present across all three joints and is likely the fundamental source of altered gait patterns in PAD. Muscle weaknesses in the plantar flexors (gastrocnemius and soleus), knee extensors (quadriceps), hip flexors (illiopasoas and anterior thigh muscles), and hip extensors (gluteal and posterior thigh muscles) resulted in decreased plantar flexor torque, knee extensor torque, and hip extensor torque in early stance and hip flexor torque during late stance in patients with PAD [22]. Thus, PAD has adverse gait effects that are of primary importance regardless of patient age. These findings support the hypothesis that age and PAD act synergistically, with the most significant gait alterations found among the O-PAD group. The only confounding issue is whether the amount of time the patient had PAD contributed to the worsening of the muscular function. The findings coincide with weakening of the muscles driving movement at the ankle as patients with PAD age, a likely result of the documented myopathy found in the muscles of patients with PAD [30]. As the myopathy progresses, scar tissue forms, resulting in what amounts to the overall findings of our study. An alternative explanation for slower walking speed and reduced spatiotemporal variables could be that patients with PAD are using these alterations as a compensatory strategy to avoid claudication pain.

Perhaps the most notable and important finding of the current study is that gait, in the absence of PAD and other ambulatory comorbidities, does not decline significantly with age based on advanced biomechanical analysis. Because previous studies have not excluded patients with underlying PAD and other comorbidities, our study is important in that all ambulatory comorbidities were excluded in the control population without selecting for high-functioning older control subjects. Time-distance parameters exhibited a shortening and slowing of gait, but the joint angles and joint kinetics remained mostly unchanged. This lack of differences between age groups differs from the generally accepted idea that it is normal for gait to decline as people age because of muscular changes such as sarcopenia. Previous studies that investigated kinematics in older adults have demonstrated a decreased knee ROM, ankle plantar flexion maximum, and hip extension maximum for older adult individuals [20-21]. Similarly, previous studies have found differences in joint torques in nondisabled older adults as compared with younger control subjects [12,20,31]. Interestingly and calling into question previous studies, the findings of gait decline in the aged from previous studies are consistent with findings in the current study for both younger and older patients with PAD. We believe this is due to the majority of studies examining the decline of older adult gait not excluding patients with PAD based on a simple ankle-brachial index despite the known high prevalence of PAD in the older adult population [12,20-21,31]. In contrast, significant evidence exists for marked ambulatory decline and function in older adult patients with PAD [32-34]. Therefore, it is likely that some of the older adult subjects in previous gait studies had unrecognized PAD, because 14 to 30 percent of people over $65 \mathrm{yr}$ of age have PAD [5,13]. Our results show that in nondisabled control subjects without health conditions affecting mobility, aging does not necessarily produce significant changes in gait mechanics. Therefore, our study calls into question the results of previous studies of gait dysfunction in older adults and whether gait actually does decline with age in the absence of movement pathologies.

The source of gait disability in patients with PAD, as suggested by previous studies, points to a definable muscular weakness resulting in decreased propulsion forces [17], decreased lower-limb strength [34-37], decreased hip and ankle joint torques [15,23-24], and reduced hip and ankle joint powers [22-24]. The presence of these gait deficits in a pain-free state combined with recent biochemical and histological studies of PAD muscles supports the idea of an acquired neuromuscular weakness. Specifically, there is increasing evidence that a significant muscle metabolic myopathy [38] and an axonal polyneuropathy in the lower limbs [39] exist in patients with PAD. Ultimately, the metabolic myopathy present in the PAD muscle is likely related to the chronic repetitive cycles of ischemia reperfusion. This chronic ischemia leads to mitochondriopathy of PAD muscle and is linked to oxidative damage to the muscle components [30] and axonal nerve loss [39]. These biochemical changes appear to contribute to myopathic and neurologic changes in patients with PAD. Future work will need to correlate these biochemical changes in PAD muscle with 
biomechanical gait changes and overall physical function in patients with PAD.

For this study, we chose to evaluate subjects while walking at their self-selected pace. We took this approach to closely replicate real-world conditions. Many studies have investigated the varying effects of speed during biomechanical analysis, and the effect of speed is controversial even within the biomechanics community [21]. However, it is important to note that gait differences have been found between younger and older adults regardless of whether or not the walking speeds were the same during the experimental protocol [12]. Therefore, we have attempted to obtain an accurate representation of the differences between control subjects and patients with PAD and between the younger and older groups of subjects. The older control subjects recruited for this study were carefully screened and persons with conditions affecting the lower-limb musculoskeletal system were excluded in an attempt to truly determine the effect of aging in the absence of ambulatory comorbidities. This approach may limit the generalizability of our findings since diseases of the musculoskeletal system are not uncommon in the older adult population. However, from a methodological standpoint, this approach is required to accurately differentiate the effect of PAD and aging on gait. Furthermore, aging itself may not lend itself to gait abnormalities, and if movement pathologies can be prevented, gait can be preserved even into advanced age.

\section{CONCLUSIONS}

In conclusion, our study of joint kinematics and joint kinetics indicates that patients with PAD experience significantly altered gait parameters even in a pain-free state, resulting in a significant ambulatory deficit definable by biomechanical analysis. The current study provides evidence that typical aging in the absence of ambulatory comorbidities may not result in a significant decline in gait function. The presence of PAD among sampled subjects may influence the data in a negative direction, leading to misguided conclusions. Therefore, previous studies must be examined in the context of potential patients with PAD being present in the population, and future ambulatory studies must include PAD as a confounding factor when assessing the gait function of elderly individuals.

\section{ACKNOWLEDGMENTS}

\section{Author Contributions:}

Study concept and design: S. A. Myers, I. I. Pipinos, J. M. Johanning. Acquisition of subjects and/or data: S. A. Myers, B. C. Applequist, J. M. Huisinga, I. I. Pipinos, J. M. Johanning.

Analysis and interpretation of data: S. A. Myers, B. C. Applequist, J. M. Huisinga, I. I. Pipinos, J. M. Johanning.

Drafting of manuscript: S. A. Myers, B. C. Applequist, J. M. Huisinga, I. I. Pipinos, J. M. Johanning.

Financial Disclosures: The authors have declared that no competing interests exist.

Funding/Support: This material was based on work supported by the American Geriatrics Society's Hartford Foundation Dennis W. Jahnigen Award (grant 1I01RX000604 to Dr. Johanning), the VA Rehabilitation Research and Development Service, the National Institutes of Health (NIH) (grant 5R01AG034995 to Dr. Pipinos), the VA Cooperative Studies Project No. 498 (award no. NCT00094575 to Dr. Pipinos), the Nebraska Research Initiative (to Dr. Myers), and the National Institute of General Medical Sciences of NIH (award no. P20GM109090 to Dr. Myers).

Institutional Review: The institutional review boards of the VA Nebraska-Western Iowa Health Care System and the University of Nebraska Medical Center approved the study. Written informed consent was obtained from all subjects before data collection.

Participant Follow-up: The authors have no plans to notify the study subjects of the publication of this article because of a lack of contact information.

Disclaimer: This material is the result of work supported with resources and the use of facilities at the VA Nebraska-Western Iowa Health Care System. The content of this article is solely the responsibility of the authors and does not necessarily represent the official views of the NIH or VA Office of Research and Development.

\section{REFERENCES}

1. Herman SD, Liu K, Tian L, Guralnik JM, Ferrucci L, Criqui MH, Liao Y, McDermott MM. Baseline lower extremity strength and subsequent decline in functional performance at 6-year follow-up in persons with lower extremity peripheral arterial disease. J Am Geriatr Soc. 2009;57(12):2246-52. [PMID:19874404] http://dx.doi.org/10.1111/j.1532-5415.2009.02562.x

2. Nehler MR, McDermott MM, Treat-Jacobson D, Chetter I, Regensteiner JG. Functional outcomes and quality of life in peripheral arterial disease: Current status. Vasc Med. 2003; 8(2):115-26. [PMID:14518614]

http://dx.doi.org/10.1191/1358863x03vm483ra

3. Nicoloff AD, Taylor LM Jr, McLafferty RB, Moneta GL, Porter JM. Patient recovery after infrainguinal bypass grafting for limb salvage. J Vasc Surg. 1998;27(2):256-63, discussion 264-66. [PMID:9510280] http://dx.doi.org/10.1016/S0741-5214(98)70356-8 
4. Toursarkissian B, Shireman PK, Harrison A, D’Ayala M, Schoolfield J, Sykes MT. Major lower-extremity amputation: Contemporary experience in a single Veterans Affairs institution. Am Surg. 2002;68(7):606-10. [PMID:12132742]

5. Hirsch AT, Criqui MH, Treat-Jacobson D, Regensteiner JG, Creager MA, Olin JW, Krook SH, Hunninghake DB, Comerota AJ, Walsh ME, McDermott MM, Hiatt WR. Peripheral arterial disease detection, awareness, and treatment in primary care. JAMA. 2001;286(11):1317-24.

[PMID:11560536]

http://dx.doi.org/10.1001/jama.286.11.1317

6. U.S. Census Bureau. Selected social characteristics in the United States: 2006-2008: 2006-2008 American community survey 3-year estimates [Internet]. Washington (DC): U.S. Census Bureau; 2008 [cited 2008 Aug 28]. Available from: http://factfinder.census.gov/faces/tableservices/jsf/pages/ productview.xhtml?pid=ACS 08 3YR DP3YR2\&prodType $=$ table

7. Byrne JE, Stergiou N, Blanke D, Houser JJ, Kurz MJ, Hageman PA. Comparison of gait patterns between young and elderly women: An examination of coordination. Percept Mot Skills. 2002;94(1):265-80. [PMID:11883574] http://dx.doi.org/10.2466/pms.2002.94.1.265

8. Elble RJ, Thomas SS, Higgins C, Colliver J. Stride-dependent changes in gait of older people. J Neurol. 1991;238(1):1-5.

[PMID:2030366] http://dx.doi.org/10.1007/BF00319700

9. Gibbon CA, Puniello MS, Krebs DE. Mechanical energy transfer during gait in relation to strength impairment and pathology in elderly women. Clin Biomech (Bristol, Avon). 2001;16(4):324-33. [PMID:11358620] http://dx.doi.org/10.1016/S0268-0033(01)00004-3

10. Whittle MW. Gait analysis: An introduction. 3rd ed. Oxford (England): Butterworth-Heinemann; 2002.

11. Winter DA, Eng P. Kinetics: Our window into the goals and strategies of the central nervous system. Behav Brain Res. 1995;67(2):111-20. [PMID:7779286] http://dx.doi.org/10.1016/0166-4328(94)00154-8

12. DeVita P, Hortobagyi T. Age causes a redistribution of joint torques and powers during gait. J Appl Physiol (1985). 2000;88(5):1804-11. [PMID:10797145]

13. Rosamond W, Flegal K, Friday G, Furie K, Go A, Greenlund K, Haase N, Ho M, Howard V, Kissela B, Kittner S, LloydJones D, McDermott M, Meigs J, Moy C, Nichol G, O’Donnell CJ, Roger V, Rumsfeld J, Sorlie P, Steinberger J, Thom T, Wasserthiel-Smoller S, Hong Y; American Heart Association Statistics Committee and Stroke Statistics Subcommittee. Heart disease and stroke statistics_-2007 update: A report from the American Heart Association Statistics Committee and Stroke Statistics Subcommittee. Circulation. 2007;115(5):e69-171. Erratum in Circulation. 2007;115(5): e172. [PMID:17194875]
14. Celis R, Pipinos II, Scott-Pandorf MM, Myers SA, Stergiou N, Johanning JM. Peripheral arterial disease affects kinematics during walking. J Vasc Surg. 2009;49(1):127-32. [PMID:19028062]

http://dx.doi.org/10.1016/j.jvs.2008.08.013

15. Chen SJ, Pipinos I, Johanning J, Radovic M, Huisinga JM, Myers SA, Stergiou N. Bilateral claudication results in alterations in the gait biomechanics at the hip and ankle joints. J Biomech. 2008;41(11):2506-14. [PMID:18586253] http://dx.doi.org/10.1016/j.jbiomech.2008.05.011

16. Gardner AW, Forrester L, Smith GV. Altered gait profile in subjects with peripheral arterial disease. Vasc Med. 2001; 6(1):31-34. [PMID:11358158]

http://dx.doi.org/10.1177/1358836X0100600106

17. Scott-Pandorf MM, Stergiou N, Johanning JM, Robinson L, Lynch TG, Pipinos II. Peripheral arterial disease affects ground reaction forces during walking. J Vasc Surg. 2007; 46(3):491-99. [PMID:17826236] http://dx.doi.org/10.1016/j.jvs.2007.05.029

18. McDermott MM, Fried L, Simonsick E, Ling S, Guralnik JM. Asymptomatic peripheral arterial disease is independently associated with impaired lower extremity functioning: The Women's Health and Aging Study. Circulation. 2000;101(9):1007-12. [PMID:10704168] http://dx.doi.org/10.1161/01.CIR.101.9.1007

19. Crowther RG, Spinks WL, Leicht AS, Quigley F, Golledge J. Relationship between temporal-spatial gait parameters, gait kinematics, walking performance, exercise capacity, and physical activity level in peripheral arterial disease. J Vasc Surg. 2007;45(6):1172-78. [PMID:17543681] http://dx.doi.org/10.1016/j.jvs.2007.01.060

20. Judge JO, Ounpuu S, Davis RB 3rd. Effects of age on the biomechanics and physiology of gait. Clin Geriatr Med. 1996;12(4):659-78. [PMID:8890109]

21. Kerrigan DC, Todd MK, Della Croce U, Lipsitz LA, Collins JJ. Biomechanical gait alterations independent of speed in the healthy elderly: Evidence for specific limiting impairments. Arch Phys Med Rehabil. 1998;79(3):317-22. [PMID:9523785] http://dx.doi.org/10.1016/S0003-9993(98)90013-2

22. Koutakis P, Johanning JM, Haynatzki GR, Myers SA, Stergiou N, Longo GM, Pipinos II. Abnormal joint powers before and after the onset of claudication symptoms. J Vasc Surg. 2010;52(2):340-47. [PMID:20670775] http://dx.doi.org/10.1016/j.jvs.2010.03.005

23. Koutakis P, Pipinos II, Myers SA, Stergiou N, Lynch TG, Johanning JM. Joint torques and powers are reduced during ambulation for both limbs in patients with unilateral claudication. J Vasc Surg. 2010;51(1):80-88. [PMID:19837536] http://dx.doi.org/10.1016/j.jvs.2009.07.117

24. Wurdeman SR, Koutakis P, Myers SA, Johanning JM, Pipinos II, Stergiou N. Patients with peripheral arterial disease exhibit reduced joint powers compared to velocity-matched 
controls. Gait Posture. 2012;36(3):506-9. [PMID:22677467] http://dx.doi.org/10.1016/j.gaitpost.2012.05.004

25. Wurdeman SR, Myers SA, Johanning JM, Pipinos II, Stergiou N. External work is deficient in both limbs of patients with unilateral PAD. Med Eng Phys. 2012;34(10):1421-26. [PMID:22321812] http://dx.doi.org/10.1016/j.medengphy.2012.01.004

26. Jeannotte L, Moore MJ; Centers for Disease Control and Prevention; Merck Company Foundation. The state of aging and health in America 2007. Whitehouse Station (NJ): The Merck Company Foundation; 2007.

27. Nigg BM, Cole GK, Nachbauer W. Effects of arch height of the foot on angular motion of the lower extremities in running. J Biomech. 1993;26(8):909-16. [PMID:8349716] http://dx.doi.org/10.1016/0021-9290(93)90053-H

28. Vaughan CL, Davis BL, O’Connor JC. Dynamics of human gait. Champaign (IL): Human Kinetics Publishers; 1992.

29. Gardner AW, Montgomery PS. The relationship between history of falling and physical function in subjects with peripheral arterial disease. Vasc Med. 2001;6(4):223-27. [PMID:11958387] http://dx.doi.org/10.1177/1358836X0100600404

30. Pipinos II, Judge AR, Zhu Z, Selsby JT, Swanson SA, Johanning JM, Baxter BT, Lynch TG, Dodd SL. Mitochondrial defects and oxidative damage in patients with peripheral arterial disease. Free Radic Biol Med. 2006;41(2):262-69. [PMID:16814106] http://dx.doi.org/10.1016/j.freeradbiomed.2006.04.003

31. Kerrigan DC, Lee LW, Nieto TJ, Markman JD, Collins JJ, Riley PO. Kinetic alterations independent of walking speed in elderly fallers. Arch Phys Med Rehabil. 2000;81(6): 730-35. [PMID:10857514] http://dx.doi.org/10.1016/S0003-9993(00)90101-1

32. Garg PK, Liu K, Tian L, Guralnik JM, Ferrucci L, Criqui MH, Tan J, McDermott MM. Physical activity during daily life and functional decline in peripheral arterial disease. Circulation. 2009;119(2):251-60. [PMID:19118256] http://dx.doi.org/10.1161/CIRCULATIONAHA.108.791491

33. McDermott MM, Ferrucci L, Guralnik J, Tian L, Liu K, Hoff F, Liao Y, Criqui MH. Pathophysiological changes in calf muscle predict mobility loss at 2-year follow-up in men and women with peripheral arterial disease. Circulation. 2009;120(12):1048-55. [PMID:19738138] http://dx.doi.org/10.1161/CIRCULATIONAHA.108.842328

34. McDermott MM, Hoff F, Ferrucci L, Pearce WH, Guralnik JM, Tian L, Liu K, Schneider JR, Sharma L, Tan J, Criqui MH. Lower extremity ischemia, calf skeletal muscle characteristics, and functional impairment in peripheral arterial disease. J Am Geriatr Soc. 2007;55(3):400-406.

[PMID:17341243] http://dx.doi.org/10.1111/j.1532-5415.2007.01092.x
35. Atkins LM, Gardner AW. The relationship between lower extremity functional strength and severity of peripheral arterial disease. Angiology. 2004;55(4):347-55.

[PMID:15258680]

http://dx.doi.org/10.1177/000331970405500401

36. McDermott MM, Ferrucci L, Guralnik JM, Tian L, Green D, Liu K, Tan J, Liao Y, Pearce WH, Schneider JR, Ridker P, Rifai N, Hoff F, Criqui MH. Elevated levels of inflammation, d-dimer, and homocysteine are associated with adverse calf muscle characteristics and reduced calf strength in peripheral arterial disease. J Am Coll Cardiol. 2007;50(9):897-905. [PMID:17719478]

http://dx.doi.org/10.1016/j.jacc.2007.05.017

37. McDermott MM, Tian L, Ferrucci L, Liu K, Guralnik JM, Liao Y, Pearce WH, Criqui MH. Associations between lower extremity ischemia, upper and lower extremity strength, and functional impairment with peripheral arterial disease. J Am Geriatr Soc. 2008;56(4):724-29.

[PMID:18284536]

http://dx.doi.org/10.1111/j.1532-5415.2008.01633.x

38. Brass EP, Hiatt WR. Acquired skeletal muscle metabolic myopathy in atherosclerotic peripheral arterial disease. Vasc Med. 2000;5(1):55-59. [PMID:10737157] http://dx.doi.org/10.1177/1358836X0000500109

39. Weber F, Ziegler A. Axonal neuropathy in chronic peripheral arterial occlusive disease. Muscle Nerve. 2002;26(4): 471-76. [PMID:12362411]

http://dx.doi.org/10.1002/mus.10235

Submitted for publication February 15, 2015. Accepted in revised form July 1, 2015.

This article and any supplementary material should be cited as follows:

Myers SA, Applequist BC, Huisinga JM, Pipinos II, Johanning JM. Gait kinematics and kinetics are affected more by peripheral arterial disease than by age. J Rehabil Res Dev. 2016;53(2):229-38.

http://dx.doi.org/10.1682/JRRD.2015.02.0027

ORCID: Sara A. Myers, PhD: 0000-0002-2934-2624; Bryon C. Applequist, MS: 0000-0003-0391-5559; Jessie M. Huisinga, PhD: 0000-0002-4249-1421; Iraklis I. Pipinos, MD: 0000-0001-6873-6346; Jason M. Johanning, MD: 0000-0002-2612-0954

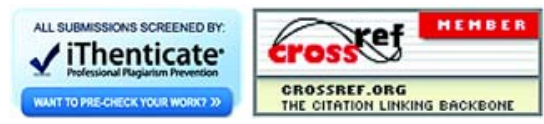

